\title{
PHYSIOLOGICAL STUDIES ON ASPERGILLUS NIGER FERMENTATION WITH POLYMER ADDITIVE
}

\author{
H. ELMAYERGI ${ }^{1}$ AND J.M. SCHARER \\ Department of Chemical Engineering, University of Waterloo, \\ Ontario, Canada
}

(Received May 14, 1973)

\begin{abstract}
When a water-soluble polymer ("Carbopol") was added to the growth medium of Aspergillus niger, significant enhancement in the rates of cellular growth and amylase production were observed. The role of the polymer additive in the system was not due to its utilization as a source of energy, neither to removal of toxic metabolic byproduct. Furthermore, it did not alter the respiratory quotient nor did it affect the overall enzyme system for respiration. Gross morphological changes from discrete pellets to filamentous growth was the only accountable parameter for yield enhancement.
\end{abstract}

The morphology of mold growth in submerged aerobic fermentation was reported to be markedly affected by the presence of nonionic surface-active agents $(1-3)$. The addition of small amounts of these surfactants to the culture medium changed the pattern of growth from pellets to pulpy or filamentous form with consequent increase in the yield factor. REESE and MAGUIRE (4) postulated the yield enhancement of extracellular enzymes to be due to the increase of membrane permeability by the surfactants. Watersoluble polymers had also exhibited similar effect in penicillin fermentation (5). However, the physiological scrutiny of these additives seems to be lacking in the available literature. Of the 17 water-soluble polymer additives and 7 surfactants examined by the authors (6), carboxy polymethylene (Carbopol) which is an anionic polymer was found to cause significant enhancement of the different growth factors investigated during the submerged fermentation of Aspergillus niger.

This article deals with the influence of such additive on some of the physiological and biophysical parameters affecting the metabolic rates.

1 Present address: Escuela de Ingeniería Quimíca, Universidad de Oriente, Puerto La Cruz, Venezuela 


\section{MATERIALS AND METHODS}

Organism. Aspergillus niger NRRL 337 (ATCC 10254, Maryland, U.S.A.), an amylase-producing strain, was used throughout.

Growth media and cultivation methods. The basic synthetic medium (A) was that developed by TosONI and GLOSS ( 7 ), whose written permission was obtained for its use, which is essentially a basal glucose-inorganic salt medium. Medium (B) was Wort broth (Difco), medium (C) was recommended by BLAKEBROUGH and HAMER $(8)$, and medium (D) was used by SHU and JoHNSON (9). The culture medium containing the polymer (Carbopol solution) was prepared by adding $0.3 \%(\mathrm{w} / \mathrm{v})$ Carbopol- $934^{2}$ to the liquid medium, then dispersed with a T-line stirrer till completely suspended before sterilization. Standard spore suspension $\left(2.8 \times 10^{3}\right.$ spores $\left./ \mathrm{ml}\right)$ was used as inoculum. All experiments were conducted in $300-\mathrm{ml}$ conical flasks $(100 \mathrm{ml}$ medium) and incubated in a water-bath shaker. Temperature was kept constant at $30^{\circ}$.

Analytical methods. The mycelial growth during fermentation was followed by measuring the dry weight of biomass. Sterile air was bubbled through the liquid medium and the evolved $\mathrm{CO}_{2}$ was monitored in the effluent gas by a conductivity method (10). The concentration of $\alpha$-amylase was measured by the method of FELLER et al. (11) and the respiration rates by manometric techniques using the Warburg respirometer (12). The concentration of Carbopol was determined by adding $12 \mathrm{ml}$ of $0.1 \mathrm{M}$ citrate buffer $(\mathrm{pH} 3.0)$ to $8 \mathrm{ml}$ of Carbopol solution and measuring the optical density at 600 $\mathrm{nm}$, then extrapolated from a standard curve.

\section{RESULTS AND DISCUSSION}

\section{Enhancement effect of carbopol}

During the course of fermentation, changes in the $\mathrm{pH}$ and amylase production were investigated as shown in Fig. 1. It appears that the addition of Carbopol to medium A (control) did not alter the general pattern. The larger decrease in the $\mathrm{pH}$ and increase of amylase excretion in comparison to control was due to a higher growth rate.

Carbopol was added to different growth media to study the applicability of its effect. Three media along with control were examined with and without Carbopol and incubated for 4 days. The maximum specific growth rate $\left(\mu_{\max }\right), \mathrm{pH}$, and morphology of growth were estimated. Triplicate runs were conducted for each medium and results are presented in Table 1 . The tendency to change from discrete pellets to a pulpy or more dispersed form, with consequent increase in the total interfacial area of growth, in the presence of the additive seems in good agreement with that reported by TAKAHASHI et al. (2). It should be pointed out that the polymer addition had slightly reduced the surface tension of the medium ( 68 and $61.8 \mathrm{dyn} / \mathrm{cm}$ for control and Carbopol solution, respectively).

\footnotetext{
2 B. F. Goodrich, Cleveland, Ohio, U.S.A.
} 


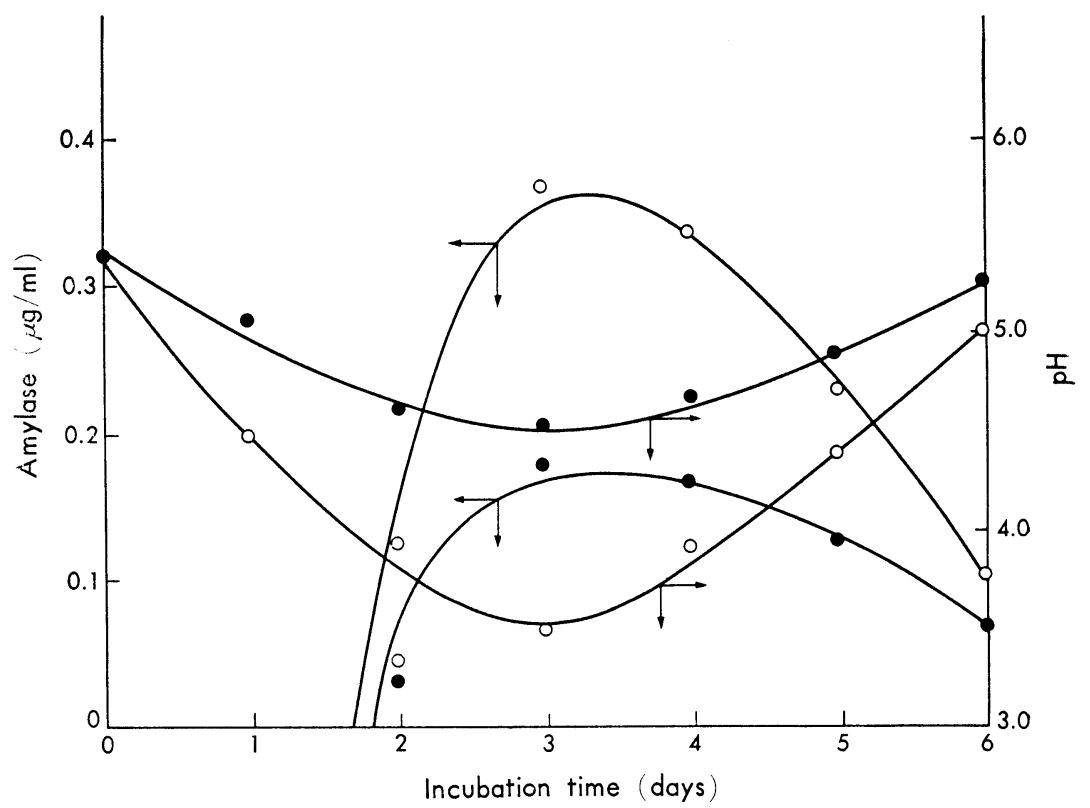

Fig. 1. Effect of fermentation time on the $\mathrm{pH}$ and amylase production.

- control; $\bigcirc$, Carbopol solution.

Table 1. Effect of Carbopol in different growth media.

\begin{tabular}{|c|c|c|c|c|}
\hline Medium for growth & $\begin{array}{c}\text { Initial } \\
\mathrm{pH}\end{array}$ & $\begin{array}{l}\text { Final } \\
\mathrm{pH}\end{array}$ & $\underset{\left(\mathrm{hr}^{-1}\right)}{\mu_{\max }}$ & $\begin{array}{l}\text { Morphology } \\
\text { of growth }\end{array}$ \\
\hline Medium $\mathrm{A}$, no additive & 5.3 & 5.1 & 0.041 & Discrete \\
\hline $\mathrm{A}+0.3 \%$ Carbopol & 5.3 & 5.0 & 0.088 & Pulpy \\
\hline Medium $B$, no additive & 4.8 & 4.6 & 0.053 & Discrete \\
\hline $\mathrm{B}+0.3 \%$ Carbopol & 4.8 & 3.9 & 0.091 & Pulpy \\
\hline Medium $\mathrm{C}$, no additive & 4.8 & 4.0 & 0.260 & Discrete \\
\hline $\mathrm{C}+0.3 \%$ Carbopol & 4.8 & 3.8 & 0.410 & Pulpy \\
\hline Medium $\mathrm{D}$, no additive & 4.6 & 3.9 & 0.142 & Discrete \\
\hline $\mathrm{D}+0.3 \%$ Carbopol & 4.6 & 3.4 & 0.206 & Pulpy \\
\hline
\end{tabular}

\section{Carbopol as an energy source or detoxification agent}

In the absence of glucose, which was the sole energy-yielding substrate in the control medium, Carbopol alone did not initiate the growth of $A$. niger. Furthermore, the concentration of Carbopol at the end of fermentation did not deviate from that added initially as shown in Fig. 2. The decrease of Carbopol 


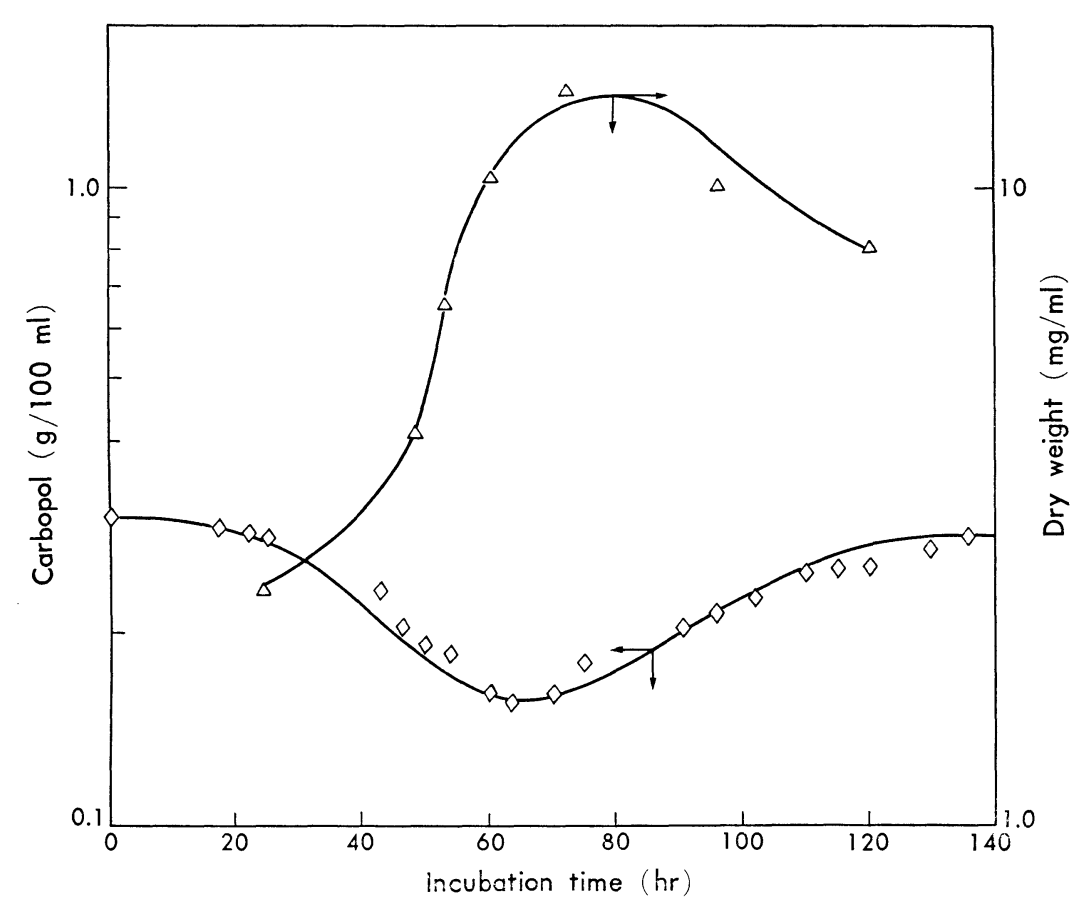

Fig. 2. Variations of Carbopol concentration in bulk liquid and biomass during fermentation.

in the liquid during the logarithmic phase of growth was due to physical adsorption of the polymer molecules to the pellet surface (6).

Some authors believed that enhancement of the yield was only brought about by the removal of toxic metabolic by-products (mainly organic acids, i.e., pyruvic) and the addition of fresh nutrients $(13,14)$. If the same principles would apply, polymer molecules might adsorb some of these acids, thus achieving such enhancement. A feasible way to study such a phenomenon is by adding activated charcoal to the growth medium and compare the results with the polymer additive. Different concentrations of activated charcoal were added to control and incubated for 4 days. Results are reported in Table 2. Particles of charcoal seemed to function as nucleation centers for the spores to grow around since significantly larger number of discrete pellets were formed as compared to the control.

\section{Effect of glucose concentration}

$\mathrm{CO}_{2}$ may be considered the main gaseous product of aerobic respiration. If Carbopol has any physiological effect on $A$. niger, such as synthesizing new enzymes for metabolic activities, different values of the Michaelis-Menten con- 
Table 2. Effect of activated charcoal on fermentation of A. niger.

\begin{tabular}{|c|c|c|c|}
\hline \multicolumn{2}{|c|}{ Concentration $(\mathrm{w} / \mathrm{v})$} & $\mu_{\max }\left(h r^{-1}\right)$ & $\mathrm{K}_{\mathrm{CO}_{2}}{ }^{a}\left(\mathrm{hr}^{-1}\right)$ \\
\hline \multicolumn{2}{|c|}{ Control } & 0.055 & 1.80 \\
\hline "I & $+0.1 \%$ Charcoal & 0.048 & 2.04 \\
\hline$\prime \prime$ & $+0.2 \%$ & 0.052 & 2.30 \\
\hline$\prime \prime$ & $+0.3 \%$ & 0.052 & 2.20 \\
\hline$\prime \prime$ & $+0.4 \%$ & 0.054 & 2.90 \\
\hline$\prime \prime$ & $+0.3 \%$ Carbopol & 0.110 & 5.60 \\
\hline
\end{tabular}

a Specific rate of $\mathrm{CO}_{2}$ evolution.

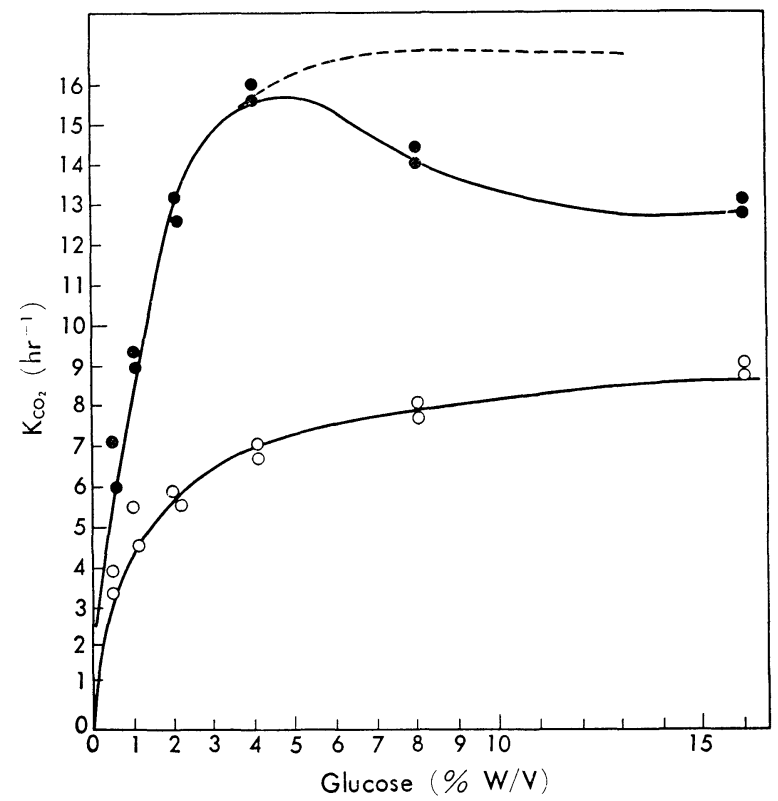

Fig. 3. The dependence of respiration on substrate concentration in control (O) and Carbopol solution

stant $\left(K_{m}\right)$ should result. The evolved $\mathrm{CO}_{2}$ was estimated in duplicate for various concentrations of glucose $(0.28$ to $0.88 \mathrm{~mol})$. All other experimental conditions were kept constant. The initial velocity of $\mathrm{CO}_{2}(\mathrm{v})$ was evaluated, from which the specific rate of $\mathrm{CO}_{2}$ evolution $\left(\mathrm{K}_{\mathrm{CO}_{2}}\right)$ was calculated and plotted $v s$. glucose concentration as shown in Fig. 3. For Carbopol solution, the maximum value of $\mathrm{K}_{\mathrm{CO}_{2}}\left(V_{\max }\right)$ was reached at $4 \%$ glucose, then decreased. This criterion might be due to the diminishing of dissolved oxygen in the 


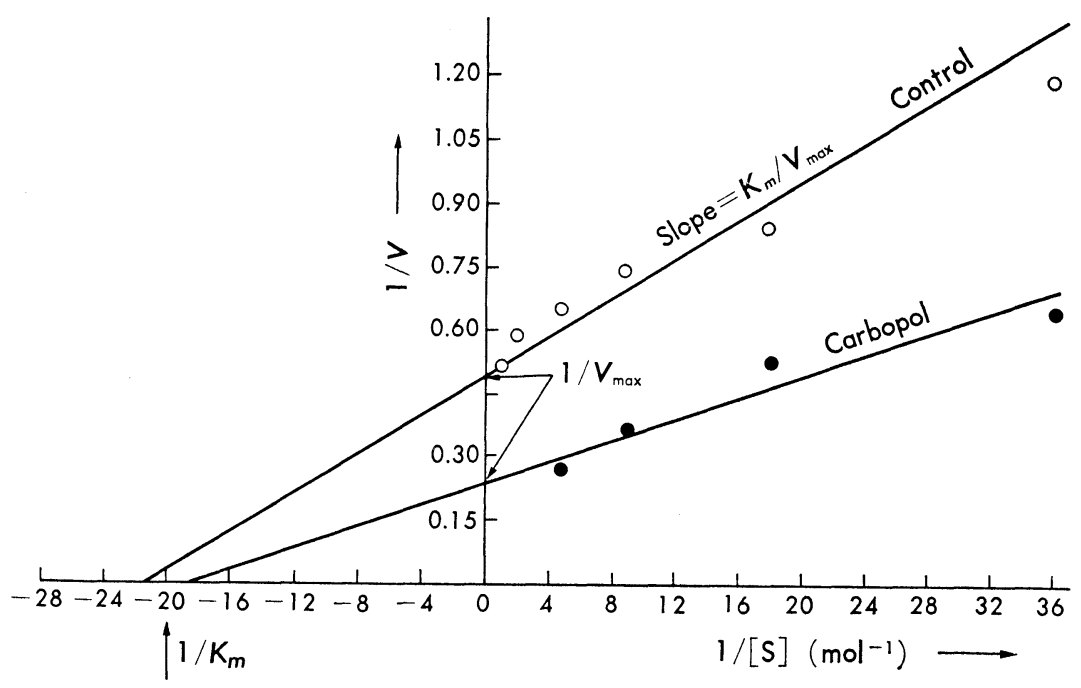

Fig. 4. The Lineweaver-Burk plot of the inverse rate of $\mathrm{CO}_{2}$ evolution vs. glucose concentration.

presence of excess energy source, which is better known as the Pasteur effect (15). In such a case, accurate $K_{m}$ can only be estimated from plotting $1 / v$ vs. $1 / s$ ( $s$ is the mol concentration of glucose), which conforms to the Lineweaver-Burk plot (16), as shown in Fig. 4. Data points were slightly scattered, thus the line of the best fit, slope, and intercepts were calculated. The estimated values of $K_{m}$ in the two liquid media investigated remained virtually uneffected $(0.046$ and 0.053 mole glucose for control and Carbopol solution, respectively). The maximum specific rate of $\mathrm{CO}_{2}$ evolution $\left(V_{\max }\right)$ was doubled in the presence of Carbopol, probably due to higher interfacial area of mycelial growth per unit volume of medium $\left(314 \mathrm{~mm}^{2} / \mathrm{cm}^{3}\right.$ from Carbopol and 121.86 $\mathrm{mm}^{2} / \mathrm{cm}^{3}$ for control).

\section{Effect of temperature}

The amount of the respired $\mathrm{CO}_{2}$ was estimated at different incubation temperature $\left(25-37^{\circ}\right)$. The growth medium was supplemented with $0.9 \%(\mathrm{w} / \mathrm{v})$ glucose. Activation energy of respiration $\left(E_{a}\right)$ was calculated from the familiar Arrhenius plot, as shown in Fig. 5. At high incubation temperature, slight inactivation of the respiratory enzymes was observed. Similar conduct was also reported for the respiration of Penicillium chrysogenum (17). It seems that higher activation energy $(1.07 \mathrm{kcal} / \mathrm{mol})$ was required to reduce the hindrance to the nutrient transfer exhibited by discrete pellets of control as compared to filamentous growth of Carbopol $(0.27 \mathrm{kcal} / \mathrm{mol})$. 


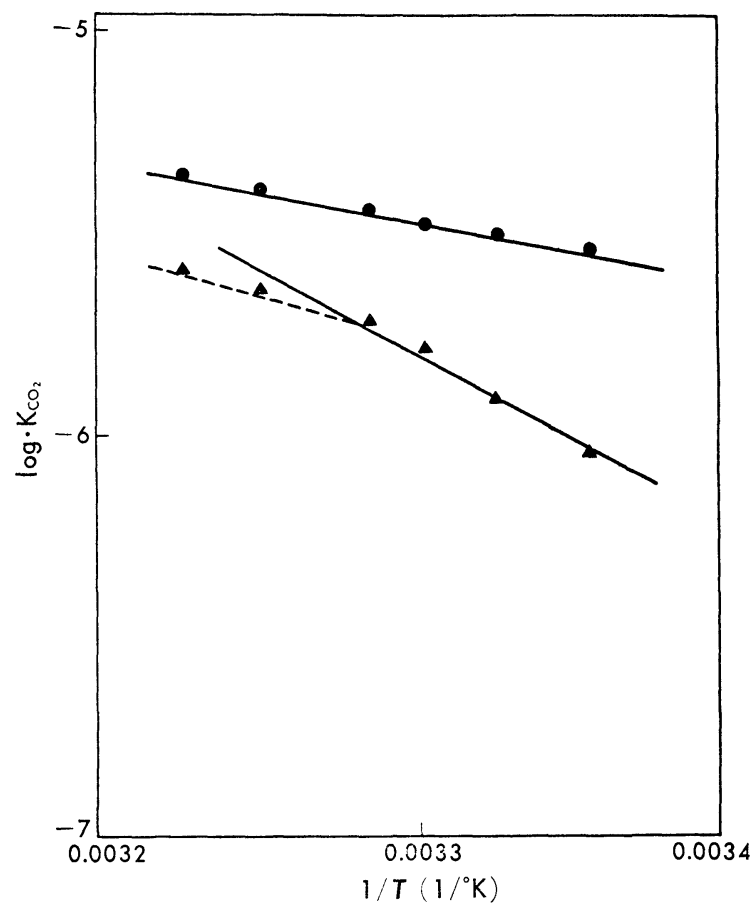

Fig. 5. Effect of different incubation temperatures on the rate of $\mathrm{CO}_{2}$ evolution in control $(\boldsymbol{\Delta})$ and Carbopol solution

\section{Respiratory quotients}

Under aerobic fermentation, the respiratory quotient (RQ) is considered to be an important physiological parameter. The Warburg respirometer was used for the determination of the rates of oxygen uptake and $\mathrm{CO}_{2}$ evolution. Estimated values of RQ were similar for control and Carbopol solution (1.252 and 1.294 , respectively). Few trials were carried out with disrupted mycelium as inoculum, from which the oxygen demand by $A$. niger in either liquid medium was shown to be constant $(65 \mu \mathrm{l} \mathrm{O} / \mathrm{mg} \cdot \mathrm{hr})$. This was taken as additional evidence for the lack of physiological effect of Carbopol on growth.

Based on the parameters investigated in this study, it would appear therefore, that the overall metabolic pathway was not altered by Carbopol. On the other hand, evidence suggested that physical factors have had a dominant effect on the yield as revealed by larger interfacial area of growth.

The authors are grateful to the National Research Council of Canada for a research grant which supported this study. 


\section{REFERENCES}

1) J. Takahashi, H. Hidaka, and K. Yamada, Agr. Biol. Chem. (Tokyo), 29, 331 (1965).

2) J. Takahashi, G. Abekawa, and K. Yamada, J. Agr. Chem. Soc. Japan, 34, 1043 (1960), in Japanese.

3) J. TAkahashi, J. Kobayashi, K. Imada, and K. Yamada, Agr. Biol. Chem. (Tokyo), 25, 141 (1961).

4) E. Reese and A. Maguire, J. Appl. Microbiol., 17, 242 (1969).

5) C. Botri, L. Cieri, and F. Giordani, Farmoco ed. Prot., 19, 507 (1964).

6) H. Elmayergi and M. Moo-Young, Advances in Microbiol., Eng. Symp., Czechoslovakia (1972).

7) A. Tosoni and D. Gloss, Can. Pat. 671, 647 (1963).

8) N. Blakebrough and J. Hamer, Biotech. Bioeng., 5, 59 (1963).

9) P. Shu and M. Johnson, Ind. Eng. Chem., 40, 1202 (1948).

10) H. Elmayergi and R. Smith, Can. J. Microbiol., 17, 1067 (1971).

11) K. Feller, M. Richter, and C. Ruttlof, Anal. Abstr., 11, 2324 (1964).

12) W. Umbreit, R. Burris, and J. Stauffer, Manometric Techniques, Burgess Publishing Co., Minneapolis, (1964), p. 28.

13) D. Gallup and P. Gerhardt, J. Appl. Microbiol., 11, 506 (1963).

14) D. Herold, Schultz, and P. Gerhardt, J. Appl. Microbiol., 15, 1192 (1967).

15) F. QuAstel, Membrane Transport and Metabolism, Academic Press, New York (1961), p. 511.

16) S. AibA, A. Humphrey, and N. Millis, Biochemical Engineering, Academic Press, New York (1965), p. 511.

17) C. Calam, N. Driver, and R. Bowers, J. Appl. Chem., 1, 209 (1951). 